\title{
INTERNACIONALIZAÇÃO DA EDUCAÇÃO SUPERIOR: GERAÇÃO SEM FRONTEIRAS
}

\section{Eloisa Fernández'; Ivan Rocha Neto²}

1. Analista de Ciência e Tecnologia da Coordenação de Aperfeiçoamento de Pessoal de Nível Superior (CAPES), Doutoranda do Programa de Pós-Graduação em Educação em Ciências: Química da Vida e Saúde, da Universidade Federal do

Rio Grande do Sul - UFRGS - Porto Alegre/RS, Brasil.

(elo2006nandez@hotmail.com).

2. PhD em Eletrônica, professor da Universidade Federal do Rio Grande do Sul

(UFRGS) - Porto Alegre/RS, Brasil.

Recebido em: 08/09/2015 - Aprovado em: 14/11/2015 - Publicado em: 01/12/2015

DOI: http://dx.doi.org/10.18677/Enciclopedia_Biosfera_2015_062

\begin{abstract}
RESUMO
O presente artigo teve por finalidade analisar a trajetória dos bolsistas egressos da graduação sanduíche e as avaliações feitas sobre o programa Ciência sem Fronteiras, de bolsas concedidas pela Coordenação de Pessoal de Nível Superior (CAPES), no período de 2011 e 2012, dos países Alemanha, Estados Unidos, França, Itália e Reino Unido, na área de conhecimento em Engenharia Elétrica. A metodologia adotada foi de natureza quantitativa, elaborada com base na estatística descritiva, também qualitativa, exploratória e documental por meio dos relatórios finais de atividades dos bolsistas e dos relatórios de avaliações de aproveitamento de crédito. As respostas extraídas dos relatórios dos ex-bolsistas não somente proveram informações sobre a continuidade dos estudos dos bolsistas, como também geraram dados sobre a formação dos alunos, inserção profissional e o desenvolvimento na carreira acadêmica para mestrado e doutorado. A partir do estudo foi possível avaliar as expectativas dos bolsistas com a experiência em estudar no exterior, bem como sugerir propostas que possam ajustar a política pública de internacionalização das instituições de ensino superior brasileiras.
\end{abstract}

PALAVRAS-CHAVE: Bolsistas egressos; educação superior; graduação sanduíche; Programa Ciência sem Fronteiras.

\section{INTERNATIONALIZATION OF HIGHER EDUCATION: SCIENCE WITHOUT BORDERS PROGRAM}

\begin{abstract}
The current paper aimed at analyzing the paths of students who received scholarships between 2011 and 2012 and were taking part of the Electric Engineering under graduation course in Germany, in the USA, in France, in Italy and the in UK, through the Sciences without Borders program, a CAPES project that granted scholarships and its assessments were also part of the analysis. The methodology was quantitative, based on descriptive analysis as well as qualitative, exploratory and documental using the students' final reports and reports on
\end{abstract}


assessment of former attended courses. The answers provided on students' final reports not only supplied information on former students who were granted scholarships and continued studying but also generated data on students' training, professional insertion and academic development in terms of Masters and Doctorate post graduate courses. It was also possible to assess students' expectations about studying abroad as well as propose suggestions that may signal adjustments in the Brazilian public internationalization policy of higher education institutions.

KEYWORDS: Scholarship graduate student; Graduation; Sandwich graduation; Program Science Without Borders.

\section{INTRODUÇÃO}

A internacionalização é uma alternativa estratégica para uma educação que promove a crítica, ativa e emancipatória, a fim de contribuir para a justiça social, para o desenvolvimento sustentável e para a democratização dos direitos de cidadania no Brasil. Uma sociedade democrática forte demanda cidadãos que participam ativamente da vida pública. A internacionalização da educação superior na perspectiva de sistemas de educação pode ser compreendida em termos de modelos. O modelo de Cooperação Internacional Tradicional (CIT) caracteriza-se por relações de competitividade entre as instituições de educação superior (IES) na captação de sujeitos e de consumidores. A ênfase é posta nos contatos internacionais e nas atividades que fortalecem as IES, principalmente as de pesquisa e de pós-graduação (MOROSINI, 2011).

Os acordos firmados com instituições de ensino superior estrangeiras são de fundamental importância para o aperfeiçoando e para o desenvolvimento científico e tecnológico nacional. As cooperações firmadas, nos dias atuais, qualificam o desenvolvimento da ciência brasileira e mundial, numa época em que mercados de bens e serviços se internacionalizam, impulsionando velozmente a era da informação, que diminui fronteira e torna qualquer tipo de contato mais rápido e eficaz (FERNÁNDEZ, 2012).

Todavia, constitui uma tarefa difícil narrar sobre ciência e conhecimento científico, uma vez que novos paradigmas indagam pressupostos e procedimentos da atividade científica. Reconhece-se que conhecimento nunca é inteiramente objetivo e que os valores dos cientistas podem interferir no seu trabalho. Já se admite que os conhecimentos gerados pela ciência não são infalíveis e que os critérios para distinguir o que é científico variam ao longo do tempo. Expandir a participação dos professores pesquisadores brasileiros no mainstream da ciência constitui um dos principais desafios do presente momento para as políticas de educação (MONTEIRO, 2012).

Por outro lado, a implementação de novos programas trouxe para o Brasil um novo cenário para a política educacional. O programa Ciência sem Fronteiras (CsF) do governo federal, criado em 2011, tem como proposta pedagógica promover, por meio da concessão de bolsas de estudos, a formação de estudantes brasileiros, conferindo-Ihes a oportunidade de novas experiências educacionais e profissionais voltadas para a qualidade, o empreendedorismo, a competitividade e a inovação em áreas prioritárias e estratégicas para o Brasil; e ainda ampliar a participação e a mobilidade internacional de estudantes de cursos técnicos, graduação e pósgraduação, docentes, pesquisadores, especialistas, técnicos, tecnólogos e engenheiros, pessoal técnico-científico de empresas e centros de pesquisa e de inovação tecnológica brasileiros, para o desenvolvimento de projetos de pesquisa, estudos, treinamentos e capacitação em instituições de excelência no exterior 
(BRASIL/2011). Com a execução do programa, percebe-se novo redirecionamento da política de educação, o que fortalece a formação no exterior em áreas estratégicas. Segundo DILMA ROUSSEFF (2013), "essas áreas são aquelas nas quais o país mais precisa para o desenvolvimento científico e tecnológico, e para gerar inovação, por isso, estas foram selecionadas pelo governo na criação do programa Ciência sem Fronteiras. Ciência, tecnologia e inovação, são fundamentais para aumentar a produtividade e tornar a nossa economia cada vez mais competitiva"'.

As áreas de Engenharias e demais áreas tecnológicas foram eleitas como uma das áreas prioritárias do programa Ciência sem Fronteiras, devido ao déficit e a escassez de profissionais no Brasil. A expressão "Apagão da Engenharia" passou a ser utilizada diante da possibilidade de faltarem engenheiros para realizar os projetos necessários para dar sustentação ao crescimento econômico e de inovação no país (CANTO FILHO et al., 2012). Estudos realizados pelo Instituto de Pesquisa Econômica Aplicada (IPEA) apontam que este fenômeno restringe, atualmente, a oferta de engenheiros em meio de carreira, possivelmente impondo às firmas maior dificuldade em preencher postos de gerência e de liderança que demandem as competências normalmente associadas a esses profissionais. Ao lado de três outros potenciais, problemas paralelos (relacionados à baixa qualidade da formação, ao déficit de competências específicas e a pouca mobilidade para regiões afastadas dos grandes centros), o hiato geracional que acarreta uma reduzida oferta relativa de engenheiros entre 35 e 59 anos parece alimentar muito da percepção de escassez desses profissionais no Brasil de hoje (IPEA, 2014).

Nesse cenário a Coordenação de Aperfeiçoamento de Pessoal de Nível Superior (CAPES) e o Conselho Nacional de Desenvolvimento Científico e Tecnológico (CNPq), agências fomentadoras do programa, não só aproveitaram parcerias anteriores, como o Serviço Alemão de Intercâmbio Acadêmico (DAAD) na Alemanha (ROSA, 2008), mas também criaram novos parceiros nos países de destino, que podem ser o próprio Ministério da Educação local, agências de fomento, fundações ou cooperativas de universidades (BRASIL/2011). Essa cooperação incrementou o crescimento dos acordos internacionais para além das consequências da globalização, conquistando avanços tecnológicos e científicos, potencializando riquezas naturais estratégicas, impulsionando o desenvolvimento nacional e projetando visibilidade no cenário internacional. Uma das dificuldades enfrentadas pelas universidades brasileiras refere-se ao reconhecimento internacional. Segundo o professor GUIMARÃES ${ }^{2}$ (2014),

Para atingirmos isso, temos que dar mais ênfase à pesquisa e inovação, aproveitar a globalização para ampliar a cooperação internacional e inserir nossos estudantes em locais mais avançados, além de absorver em nossas universidades estudantes e docentes vindos do exterior. Também precisamos aumentar o acesso a conteúdos internacionais.

\footnotetext{
1 Informação retirada do Portal do Planalto, publicada em 30/09/2013, 00h00. Disponível em: $<$ http://www2.planalto.gov.br/acompanhe-o-planalto/cafe-com-a-presidenta/cafe-com-apresidenta_/cafe-com-a-presidenta-30-09-2013>. Acesso em: 25 mar.2015.

2 Pesquisador Sênior do CNPq. Percorreu toda a carreira universitária atuando como professor na UFRRJ, UNIFESP, Faculdade de Medicina de São José do Rio Preto - SP, na UNICAMP, UFF e UFRJ. Atualmente é professor titular aposentado da Universidade Federal do Rio Grande do Sul e ocupou a presidente da Coordenação de Aperfeiçoamento de Pessoal de Nível Superior (CAPES) de 2004 a 2015.
} 
A legislação brasileira determina que a educação nacional tenha por finalidade o desenvolvimento pleno do educando, preparando-o para o exercício da cidadania (BRASIL, 1988; 1996). O programa Ciência sem Fronteiras buscou propor melhores condições de ensino por meio da cooperação internacional, que pode ser benéfica para todos, por exemplo, com a abertura de perspectivas em temas emergentes de investigação, com 0 acesso aos conteúdos de informações atualizadas e aos resultados de pesquisa mais recentes. Portanto, entende-se que este estudo poderá trazer contribuições científicas para a área de política educacional de qualidade ao questionar os resultados do retorno dos bolsistas após os estudos em IES estrangeiras, e também verificar se as atuais políticas públicas de educação estão sendo efetivas no que se referem ao objetivo de preparar os educandos para o exercício de sua profissão (CIÊNCIA SEM FRONTEIRAS, 2015).

Além disso, este estudo visou analisar a trajetória e formação dos bolsistas egressos da graduação sanduíche, investigar em que medida os egressos tem atendido às demandas profissionais do Brasil e se pretendem seguir a carreira de mestrado e doutorado no país. Como se pode depreender, a proposta combina o desenvolvimento da ciência, tecnologia e inovação em temas de interesse nacional, como o processo de internacionalização, inclusive para poder atender à demanda reprimida de qualificação de pessoal nessas áreas.

\section{MATERIAL E MÉTODOS}

Para o desenvolvimento desta pesquisa, foi escolhida a abordagem quantitativa dos ex-bolsistas de graduação egressos do exterior e também qualitativa, por compreender os significados das respostas dos bolsistas enviadas por meio dos relatórios finais de atividades e dos relatórios de avaliações de aproveitamento de crédito.

As estatísticas descritivas foram extraídas do Banco de Dados da CAPES através do Sistema de Extração Dinâmica de Dados (SisRel), que permitiram selecionar 269 bolsistas de graduação sanduíche, da área de Engenharia Elétrica, de bolsas concedidas pela CAPES no período de 2011 e 2012, dos países Alemanha, Estados Unidos, França, Itália e Reino Unido. O SisRel é um sistema que tem como objetivo extrair informações de forma dinâmica e pré-formatada. $O$ conceito utilizado para o desenvolvimento é do Business intelligence, que consiste em uma camada utilizada para abstrair a utilização do banco de dados e responder informações para o usuário sem a necessidade de um conhecimento técnico e específico.

Os rankings das universidades foram extraídos das plataformas $\mathrm{THE}^{3}$ - Times Higher Education (UK) - World University Rankings 2014-2015, QS $^{4}$ - World University Rankings 2013 (UK) e Webometrics ${ }^{5}$ - Ranking Web de Universities (ES) (THE TIMES GIGHER EDUCATION , 20015)

A graduação dos bolsistas e a atividade atual foram complementadas através dos currículos dos bolsistas obtidas por meio de consultas na Plataforma Lattes ${ }^{6}$

\footnotetext{
3 THE - Times Higher Education (UK): https://www.timeshighereducation.co.uk/world-universityrankings/ Acesso em: 25 mar. 2015.

${ }^{4}$ QS - World University Rankings (UK): http://www.topuniversities.com/university-rankings - Acesso em: 25 mar. 2015.

5 WEBOMETRICS (ES): http://www.webometrics.info/es - Acesso em: 25 mar. 2015.

${ }^{6}$ Plataforma Lattes - CNPq - Conselho Nacional de Desenvolvimento Científico e Tecnológico http://lattes.cnpq.br/ Acesso em: 10 mar. 2015.
} 
(extração em 10/03/2015). As informações obtidas dos relatórios finais de atividade e dos relatórios de avaliação de aproveitamento de créditos foram coletadas do Banco de Dados da CAPES, através do sistema SAC-Egressos - Sistema de Acompanhamento de Bolsas no Exterior. O sistema SAC-Egressos tem como finalidade viabilizar o acompanhamento dos processos eletrônicos dos bolsistas após a vigência da bolsa (CNPQ, 2015).

Com base nas respostas extraídas dos relatórios finais de atividades, mediram-se as atividades praticadas e o desempenho alcançado pelos bolsistas egressos do exterior, de bolsas concedidas em 2011 e 2012, com atividades em 2012 e 2013. Foram levantados 212 relatórios de um total de 269 bolsistas egressos. A maioria das questões foi de natureza qualitativa, porque expressaram as opiniões dos egressos sobre suas experiências. É importante salientar que os relatórios finais de atividades são documentos utilizados para prestação de contas e enviados no final da concessão da bolsa. Os referidos relatórios finais são questionários específicos, compostos de questões abertas e fechadas, onde são levantadas as experiências acadêmicas e avaliados os resultados obtidos na universidade; estágios e trabalhos executados; cursos de línguas; o que representa, inclusive, uma oportunidade para que o bolsista manifeste, singularmente, suas impressões, críticas e sugestões do programa.

Para avaliar o aproveitamento de crédito das disciplinas cursadas no exterior, foram extraídas respostas relatadas através dos relatórios de avaliações de aproveitamento de crédito $^{7}$ constantes nos respectivos processos eletrônicos de bolsa. Os relatórios de aproveitamento de crédito não são documentos para prestação de contas. São questionários exploratórios, compostos de questões abertas e fechadas, que visam avaliar as disciplinas cursadas no exterior. Foram levantados 160 relatórios de um total de 269 egressos, 109 estão pendentes, não responderam ou enviaram até o término desta pesquisa.

\section{RESULTADOS E DISCUSSÃO}

A partir das informações extraídas do Sistema de Extração Dinâmica de Dados (SisRel) da CAPES, foi elaborada a Tabela 1, que demonstra o número de bolsas de graduação sanduíche das áreas de engenharias elétricas, distribuídas por país de destino. Verifica-se que os Estados Unidos encontram-se em primeira colocação com um percentual de $72,12 \%$. Em seguida classificou-se o Reino Unido com 10,41\%; a Itália com 7,81\%; a França com 5,58\% e Alemanha com 4,09\%. Segundo FERNÁNDEZ \& ROCHA NETO (2012), a escolha por esses destinos pode ser explicada pelo aspecto que envolve a realização de graduações em países do ponto de vista da eficiência do sistema de fomento e de formação de pessoal nas áreas científicas e tecnológicas para o avanço da ciência brasileira, com o objetivo de atingir patamares próximos de países como os Estados Unidos e alguns países europeus. Todavia, é importante ressaltar que o desequilíbrio entre o primeiro colocado e os demais países europeus deve-se ao fato que os Estados Unidos foram o único país contemplado, em 2011, na primeira chamada. Enquanto na segunda chamada do programa CsF, em 2012, participaram os demais países selecionados (CAPES, 2015).

\footnotetext{
7 Art. 47, § 2º, Lei de Diretrizes e Base (LDB) ํo 9.349, de 20/12/1996. Disponível em: $<$ https://www.planalto.gov.br/ccivil_03/Leis/L9394.htm> $<$ http://portal.mec.gov.br/index.php?option=com_content\&view=article\&id=12797\&ltemid=866>. 
TABELA 1 - Distribuição de bolsistas das áreas de engenharias elétricas por país de destino de bolsas concedidas no período de 2011- 2012

\begin{tabular}{ccc}
\hline País de Destino & Bolsista & Percentual \\
\hline Estados Unidos & 194 & 72,12 \\
Reino Unido & 28 & 10,41 \\
Itália & 21 & 7,81 \\
França & 15 & 5,58 \\
Alemanha & 11 & 4,09 \\
\hline Total Geral & $\mathbf{2 6 9}$ & $\mathbf{1 0 0}$ \\
\hline
\end{tabular}

Fonte: SisRel/CAPES/CGMR - Ano 2015

Com referência a distribuição de bolsistas das áreas de engenharias elétricas por áreas prioritárias, considerada na Tabela 2, nota-se que 91,08\% dos bolsistas encontram-se nas áreas de engenharias e demais áreas tecnológicas, 6,32 \% nas engenharias renováveis, $1,86 \%$ na computação e tecnologia da informação e $0,37 \%$ em biotecnologia e em nanotecnologia e novos materiais. Isso demonstra que a maior concentração de bolsistas ocorreu nas áreas de engenharias e demais áreas tecnológicas. Contudo, observa-se que os bolsistas das engenharias elétricas, também demandaram para as demais áreas. As menores demandas foram para as áreas de biotecnologia e nanotecnologia e novos materiais. Considerando a escassez de engenheiros no país, o resultado vem ao encontro à insuficiência apresentada pelo mercado de trabalho brasileiro.

TABELA 2 - Distribuição de bolsistas das áreas de engenharias elétricas por áreas prioritárias de bolsas concedidas no período de 2011- 2012

\begin{tabular}{ccc}
\hline Área prioritária & Bolsista & Percentual \\
\hline Engenharias e demais áreas tecnológicas & 245 & 91,08 \\
Energias renováveis & 17 & 6,32 \\
Computação e tecnologia da informação & 5 & 1,86 \\
Biotecnologia & 1 & 0,37 \\
Nanotecnologia e novos materiais & 1 & 0,37 \\
\hline Total Geral & $\mathbf{2 6 9}$ & $\mathbf{1 0 0}$ \\
\hline
\end{tabular}

Fonte: SisRel/CAPES/CGMR - Ano 2015

Em relação à distribuição de bolsistas por estado de origem da IES, considerada na Tabela 3, o estado de Minas Gerais classificou-se em primeiro, com 64 bolsistas. Em seguida São Paulo, com 57 bolsistas; os estados do Rio Grande do Sul e Rio de Janeiro ambos com 22 bolsistas; e Distrito Federal, com 17. O resultado dessa classificação indica que as instituições mineiras foram as que mais induziram e fomentaram a pesquisa e a inovação científica e tecnológica para o desenvolvimento do Estado, no período de 2011 - 2012, no âmbito do CsF.

TABELA 3 - Distribuição de bolsistas das áreas de engenharias elétricas por unidade de federação da IES no período de 2011- 2012

\begin{tabular}{cc}
\hline Estado de Origem & Bolsista \\
\hline Minas Gerais & 64 \\
São Paulo & 57 \\
Rio Grande do Sul & 22 \\
Rio de Janeiro & 22 \\
Distrito Federal & 17 \\
Paraíba & 15 \\
Paraná & 12 \\
Ceará & 9
\end{tabular}


Pernambuco $\quad 9$

Santa Catarina $\quad 8$

Goiás 5

Amazonas 5

Rio Grande do Norte 4

Bahia 4

Mato Grosso do Sul

Pará 4

Espírito Santo 3

Maranhão 2

Mato Grosso

Piauí 1

Amapá 1

Total Geral 269

Fonte: SisRel/CAPES/CGMR - Ano 2015

Confere-se na Tabela 4, a distribuição de bolsistas por IES de origem. Observa-se, que a USP foi à instituição que mais enviou estudantes de engenharia elétrica para o exterior, alcançando a primeira colocação com 26 bolsistas, seguida pela UNIFEI (Universidade Federal de Itajubá) com 21 e UFMG (Universidade Federal de Minas Gerais) com 18 bolsistas. Merece mencionar que, embora a USP tenha alcançado a segunda classificação na distribuição de bolsistas por IES de origem, o estado de São Paulo obteve o segundo lugar na classificação de distribuição de bolsistas por estado de origem da IES, conforme, Tabela 3, anterior.

TABELA 4 - Distribuição de bolsistas das áreas de engenharias elétricas por IES de origem no período de 2011- 2012

\begin{tabular}{cc}
\hline IES & Bolsistas \\
\hline Universidade de São Paulo & 26 \\
Universidade Federal de Itajubá & 21 \\
Universidade Federal de Minas Gerais & 18 \\
Universidade de Brasília & 17 \\
Universidade Federal de Campina Grande & 15 \\
Universidade Federal do Rio Grande do Sul & 10 \\
Universidade Federal do Ceará & 9 \\
Universidade Federal do Rio de Janeiro & 9 \\
Universidade Federal de Ouro Preto & 9 \\
Universidade Federal de Santa Catarina & 8 \\
Universidade Federal de Pernambuco & 8 \\
Centro Universitário da FEl (Priv.) & 8 \\
Universidade Tecnológica do Paraná & 8 \\
Universidade Estadual de Campinas & 7 \\
Pontifícia Universidade Católica de Minas Gerais & 6 \\
Universidade Federal de Goiás & 5 \\
Pontifícia Universidade Católica do Rio Grande do Sul (Priv.) & 5 \\
Instituto Federal ECT Fluminense & 5
\end{tabular}


Universidade Federal de Uberlândia 5

Universidade do Estado do Amazonas $\quad 5$

Fundação Universidade Federal do ABC 4

Universidade Federal do Rio Grande do Norte 4

Universidade Federal do Espírito Santo 3

Universidade Federal do Pará 3

Instituto Federal de Educação, C \& T da Bahia 3

Universidade do Estado do Rio de Janeiro 3

Universidade Católica Dom Bosco 2

Pontifícia Universidade Católica do Rio de Janeiro 2

Universidade do Vale do Rio dos Sinos 2

Instituto Federal de Educação, C \& T de São Paulo 2

Centro Federal de Minas Gerais 2

Universidade de Caxias do Sul 2

Universidade do Estado do Rio de Janeiro 2

Centro Universitário de Maringá - CEUMAR 2

Centro Federal de São Carlos 2

Universidade Federal Fluminense $\quad 2$

${ }^{*}$ Demais Instituições ${ }^{8} \quad 25$

Total Geral 269

Fonte: SisRel/CAPES/CGMR - Ano 2015

Quanto à distribuição dos bolsistas nas IES de destino, conforme Tabela 5, foram utilizados os rankings THE, QS e Webometrics para a classificação das respectivas instituições estrangeiras. Observa-se que, dentre as instituições listadas, a Politecnico Di Torino foi à instituição que mais recebeu estudantes brasileiros, com 13 bolsistas, e classificou-se em $370^{\circ}$ posição na QS e $470^{\circ}$ na Webometrics (WEBOMETRICS, 2015). Logo após, encontra-se a The Catholic University of America que recebeu sete bolsistas, contudo não foi localizada na busca dos rankings. Nota-se, também, que a Rose-Hulman Institute of Technology recebeu seis bolsistas e encontra-se na $1564^{\circ}$ posição do Webometrics, seguida pela University of Colorado - Boulder, com seis bolsistas e classificada na $45^{\circ}$ na Webo, $97^{\circ}$ na THE e 160ํㅡㄴ nS (QS TOP UNIVERSITIES, 20015). Destaca-se, que a Texas A \& M University, College Station que recebeu apenas três bolsistas foi a instituição que obteve a melhor que classificação na busca dos rankings internacionais, com a $15^{\text {a }}$ posição da Webometrics.

A questão das posições das IES estrangeiras nos rankings internacionais merece atenção porque, embora as instituições estrangeiras de destino, por sua excelência, terem sido aceitas ao serem demarcadas em adequação acadêmica, estabelecida pelas áreas específicas de cada modalidade, quando do processo realizado pela CAPES, diversos estudantes foram para instituições com ranking de classificação muito baixo. Isso pode indicar que existe uma disparidade no prestígio e na reputação científica das instituições onde foram realizadas as graduações, o que demonstra que os critérios de escolha dos bolsistas para a graduação sanduíche devem ser afinados, mais rígidos, para que se elejam instituições de

${ }^{8}$ As demais instituições são IES com menos de 2 bolsistas.

ENCICLOPÉDIA BIOSFERA, Centro Científico Conhecer - Goiânia, v.11 n.22; p.3526 
maior excelência fora do país. De fato, deve-se repensar a finalidade de enviar os alunos para Instituições piores ou iguais às brasileiras.

TABELA 5 - Distribuição de bolsistas de graduação sanduíche nas Instituições de destino e as posições das IES nos rankings internacionais

\begin{tabular}{|c|c|c|c|c|}
\hline IES estrangeira & Bolsista & THE & $\begin{array}{l}\text { QS } \\
\text { Top }\end{array}$ & $\begin{array}{c}\text { Webo } \\
\text { Metrics }\end{array}$ \\
\hline Politecnico Di Torino & 13 & ** & 370 & 470 \\
\hline The Catholic University of America & 7 & ** & $\star *$ & $* *$ \\
\hline $\begin{array}{c}\text { Rose-Hulman Institute of Technology } \\
\text { Terre Haute }\end{array}$ & 6 & ** & ** & 1564 \\
\hline University of Colorado - Boulder & 6 & 97 & 160 & 45 \\
\hline Santa Clara University & 5 & $\star \star *$ & $\star *$ & 634 \\
\hline California State University, Fullerton & 5 & ** & ** & 840 \\
\hline Tennessee Technological University & 5 & ** & ** & 1437 \\
\hline $\begin{array}{l}\text { Indiana Institute of Technology, Fort } \\
\text { Wayne }\end{array}$ & 5 & ** & ** & ** \\
\hline Lawrence Technological University & 5 & ** & ** & ** \\
\hline Newcastle of University & 5 & 298 & 129 & 660 \\
\hline Western Michigan University & 5 & $* *$ & ** & 466 \\
\hline University of Idaho & 4 & ** & ** & 405 \\
\hline State University of New York, Buffalo & 4 & ** & ** & $\star *$ \\
\hline university of massachusetts, dartmouth & 4 & ** & ** & 950 \\
\hline Kettering University & 4 & ** & ** & $\star \star$ \\
\hline The University of Alabama, Birmingham & 4 & $* *$ & $\star \star$ & ** \\
\hline Drexel University & 3 & $\begin{array}{l}301- \\
350\end{array}$ & $\begin{array}{l}401- \\
490\end{array}$ & 260 \\
\hline University of North Florida & 3 & $* \star$ & $\star \star$ & 1386 \\
\hline University of Brighton & 3 & ** & ** & 978 \\
\hline Fairfield University & 3 & ** & ** & 1349 \\
\hline Montana State University & 3 & ** & $\star \star *$ & 371 \\
\hline Illinois Institute of Technology & 3 & ** & $\begin{array}{l}441- \\
450\end{array}$ & 453 \\
\hline $\begin{array}{c}\text { Université Lille } 1 \text { - Sciences et } \\
\text { Technologies }\end{array}$ & 3 & ** & $\begin{array}{l}401- \\
410\end{array}$ & ** \\
\hline lowa State University & 3 & ** & 321 & 64 \\
\hline University of Mississippi, Oxford & 3 & ** & 317 & 506 \\
\hline Colorado State University, Fort Collins & 3 & ** & 394 & 135 \\
\hline Michigan Technological University & 3 & ** & $\begin{array}{l}551- \\
600\end{array}$ & 359 \\
\hline Texas A \& M University, College Station & 3 & ** & 153 & 15 \\
\hline University of Missouri, Kansas City & 2 & ** & $\star *$ & 608 \\
\hline${ }^{\star}$ Demais Instituições & * & * & * & * \\
\hline
\end{tabular}

Fonte: SisRel/CAPES/CGMR - Ano 2015

Para avaliar as atividades e o desempenho alcançados pelos bolsistas egressos do exterior, foram extraídos de seus processos eletrônicos os respectivos ENCICLOPÉDIA BIOSFERA, Centro Científico Conhecer - Goiânia, v.11 n.22; p.3527 
relatórios finais de atividades. Confere-se, na Tabela 6 , que $70 \%$ dos bolsistas avaliaram como ótima a infraestrutura da IES no exterior, $25 \%$ como boa e $1 \%$ como fraca. Transcreve-se, a seguir, trecho obtido por meio de resposta no campo aberto do relatório de atividades: "[...] disponibilidade das facilidades e recursos do departamento de Engenharia Elétrica para realização do projeto. Tais quais: acesso a laboratórios, disponibilidade de materiais (possibilidade de encomendar o material necessário), acesso a máquinas de alta tecnologia, entre outros. Sempre seguindo regras de segurança no trabalho e com excelente apoio do professor supervisor e de técnicos dos laboratórios [...]".

TABELA 6 - Avaliação realizada pelos egressos sobre a infraestrutura da IES no exterior no período de 2011- 2012 com atividades em 2012 - 2013

\begin{tabular}{cc}
\hline Avaliação & Percentual \\
\hline Ótima & $70 \%$ \\
Boa & $25 \%$ \\
Regular & $4 \%$ \\
Fraca & $1 \%$ \\
Péssima & $0 \%$ \\
\hline Total & $\mathbf{1 0 0 \%}$ \\
\hline
\end{tabular}

Fonte: SisRel/CAPES/CGMR - Ano 2015

Quando comparada a infraestrutura da IES no exterior com a IES brasileira, conforme Tabela 7, nota-se que 58\% dos bolsistas avaliaram como muito melhor a IES no exterior que a IES brasileira, $25 \%$ como melhor, $13 \%$ como equivalentes e $4 \%$ como pior. Destaca-se como resposta aberta: "[...] Quanto ao fato da infraestrutura da universidade do Reino Unido ser superior àquela da minha universidade no Brasil, isto se dá em parte porque a University of Bath (assim como as demais da Inglaterra) é uma universidade com recursos privados, a qual usufrui de patrocínios de empresas renomadas (Por exemplo: Um dos seus laboratórios era inteiramente equipado com equipamentos de ponta da Agilent technologies, no qual havia uma bancada de equipamentos para cada aluno). No Brasil, em parte dos laboratórios, é comum serem formados grupos de até cinco alunos para utilizarem na aula um mesmo equipamento fundamental para o aprendizado".

Os relatos parecem indicar que, embora existam no Brasil universidades de altíssimo nível, tais como USP, UFMG, UFRJ e UFRGS, entre outras, o país precisa criar mecanismos eficientes de financiamento das universidades e investir estrategicamente em Ciência e Tecnologia. Quanto mais recursos forem investidos em educação, inclusive a superior, em pesquisa e em desenvolvimento científico e tecnológico, mais se consolidam a democracia e a soberania nacional. Para isso é necessário que o Poder Público defina as regras de financiamento em uma base sólida, cujos recursos financeiros sejam suficientes para o pagamento de pessoal e para a manutenção e custeio das atividades de ensino e pesquisa com qualidade, sem, evidentemente, deixar de proporcionar o crescimento das universidades e a inclusão de mais estudantes no ensino superior. Isso é dever do Estado e da sociedade, e seria uma prova de respeito a um espaço de construção e de democratização do conhecimento (PRIORI, 2002). 
TABELA 7 - Comparação da infraestrutura da IES no exterior com a IES brasileira relatada por 212 bolsistas egressos no período de 2011 - 2012 com atividades em 2012 - 2013

\begin{tabular}{cc}
\hline Avaliação & Percentual \\
\hline Muito melhor & $58 \%$ \\
Melhor & $25 \%$ \\
Equivalente & $13 \%$ \\
Pior & $4 \%$ \\
Muito pior & $0 \%$ \\
\hline Total & $\mathbf{1 0 0 \%}$
\end{tabular}

Fonte: SisRel/CAPES/CGMR - Ano 2015

Sobre os desempenhos dos alunos alcançados na IES no exterior, mostra-se, na Tabela 8, que 52\% aferiram como ótimo, $41 \%$ como bom e $6 \%$ como regular. Na transcrição das respostas abertas, destaca-se o seguinte relato: "[...] Interagir bastante com os alunos da faculdade estrangeiras e fazer novas amizades. Mesmo que o objetivo do programa seja acadêmico, não deixar de considerar a vida pessoal; conciliar tempo de estudo com tempo pessoal para conhecer, explorar e fazer amigos. Conversar com os professores também é bem interessante, eles sempre estão por perto e não se importam de conversar com alunos sobre qualquer assunto, como aconselhamento acadêmico e outros assuntos".

TABELA 8 - Avaliação do desempenho dos bolsistas egressos da IES no exterior no período de 2011 - 2012 com atividades em 2012 - 2013

\begin{tabular}{cc}
\hline Avaliação & Percentual \\
\hline Ótimo & $52 \%$ \\
Bom & $41 \%$ \\
Regular & $6 \%$ \\
Fraco & $1 \%$ \\
Péssimo & $0 \%$ \\
\hline Total & $\mathbf{1 0 0} \%$ \\
\hline
\end{tabular}

Fonte: SisRel/CAPES/CGMR - Ano 2015

Quanto à aferição do desempenho dos bolsistas nas atividades executadas no estágio no exterior (Tabela 9), 48\% avaliaram como ótimo, 34\% como bom, $15 \%$ regular e 3\% como péssimo. Ressalta-se que, dos 269 bolsistas de Engenharia Elétrica, 131 realizaram o estágio e 81 não realizaram. Destaca-se, nas respostas abertas: "[...] facilitar ainda mais a inserção dos bolsistas nas empresas do exterior, pois houve dificuldade em conseguir um estágio. As empresas americanas não facilitam a entrada de estudantes de intercâmbio, pois não poderão dar um retorno à empresa após o período de treinamento".

TABELA 9 - Avaliação do desempenho do bolsista nas atividades executadas no estágio no período de 2011 - 2012 com atividades em 2012 - 2013

\begin{tabular}{cc}
\hline Avaliação & Percentual \\
\hline Ótimo & $48 \%$ \\
Bom & $34 \%$ \\
Regular & $15 \%$ \\
Fraco & $1 \%$ \\
Péssimo & $3 \%$ \\
\hline Total & $\mathbf{1 0 0} \%$ \\
\hline
\end{tabular}

Fonte: SisRel/CAPES/CGMR - Ano 2015 
Acerca do questionamento da proficiência após o período de estudos no exterior, nota-se (tabela 10) que $67 \%$ dos bolsistas avaliaram como muito melhor o domínio do idioma, $25 \%$ como melhor e $7 \%$ como equivalente. Destaca-se como resposta aberta: "[...] investir na língua falada antes de ir, tudo bem que o governo fornece cursos de línguas, mas sair daqui sem nenhuma carga de conhecimento é insuficiente, você vai perder um tempo valioso se for aprender do nada. Conversar frequentemente em português, dificulta e muito o aprendizado do alemão. Fazer amigos com quem possa treinar as habilidades linguísticas é a melhor coisa a se fazer, já que o alemão não é um idioma considerado fácil. Além da melhoria no uso da língua inglesa, tive uma grande melhoria no meu pessoal. Voltei de lá outra pessoa, com outra mente. Aprendi a ser mais responsável com meus deveres e a ser independente. Durante meu período no exterior, pude conviver com pessoas de diversos países e culturas e isso me fez perceber que cada cultura tem seu valor e que devemos respeitar as diferenças. Por questões de Língua e cultura, deve-se relacionar com estudantes nativos o máximo possível, esta é a melhor forma de aperfeiçoar a proficiência no idioma de destino [...]".

No âmbito das respostas colhidas, é possível identificar que talvez o problema da falta de idioma estrangeiro, como a língua inglesa, nos corredores acadêmicos, tem diminuído. Com o melhoramento da proficiência do idioma estrangeiro, as publicações e os trabalhos científicos poderão ser incluídos em bases internacionais, qualificando a produção brasileira. Os trabalhos científicos são publicados basicamente em português, com isso, quem não fala nosso idioma não consegue nos ler e nem nos citar - algo essencial na atividade científica.

TABELA 10 - Avaliação da proficiência após os estudos no exterior relatada pelos 269 alunos egressos no período de atividade 2012 - 2013 no período de 2011 - 2012 com atividades em 2012 - 2013

\begin{tabular}{cc}
\hline Avaliação & Percentual \\
\hline Muito melhor & $67 \%$ \\
Melhor & $25 \%$ \\
Equivalente & $7 \%$ \\
Pior & $1 \%$ \\
Muito pior & $0 \%$ \\
\hline Total & $\mathbf{1 0 0 \%}$ \\
\hline
\end{tabular}

Fonte: SisRel/CAPES/CGMR - Ano 2015

A Tabela 11 mostra a avaliação do bolsista acerca do desempenho geral da Capes no programa. Observa-se que $20 \%$ mediaram como ótimo o desempenho, $52 \%$ como bom e $22 \%$ como regular. Das respostas abertas obtidas, destacam-se: "[...] Minha maior reclamação à CAPES tem a ver com a comunicação entre o programa e a universidade no exterior. Os professores que nos orientavam não sabiam da necessidade de um estágio/pesquisa no período de verão. Por esse motivo, algumas pessoas como eu, foram alocadas somente com brasileiros nesse projeto, o que mina o objetivo do programa de integrar o estudo do curso com um novo idioma e fazer relações profissionais com pessoas de outras culturas. Dito isso, fica a sugestão para a CAPES para sistematizar esse processo para que os alunos não sejam prejudicados nesse sentido. Uma outra reclamação tem a ver com a comunicação com a CAPES, muitos de nós tivemos problemas em receber retorno dos nossos e-mails com dúvidas a respeito de quaisquer procedimentos. Portanto, 
peço à coordenação do programa para melhorar isso. Muitas vezes recebíamos respostas tardias com nenhuma resposta satisfatória" e "[...] O desempenho geral da CAPES/CNPQ foi muito bom. Ao chegar nos EUA, não encontrei problemas graças ao trabalho em conjunto da CAPES, IIE e minha universidade americana. Os pagamentos referentes à bolsa foram efetuados corretamente, proporcionando-me excelentes condições de estudo e estadia no exterior" "[...] De maneira geral, a CAPES me proporcionou uma experiência como a de estudar por um ano num país diferente e isso não pode ser encarada apenas como uma atividade acadêmica, trata-se de uma experiência de vida completa [...].

Foi possível verificar que os bolsistas consideram boa a atuação da CAPES e que programa Ciência sem Fronteiras foi de grande experiência em suas vidas, tanto pessoal quanto profissional. Foram otimistas em seus depoimentos, mas, ao mesmo tempo, preocupados com a possibilidade de difundir os conhecimentos adquiridos no retorno ao Brasil, de poderem contribuir com o ensino na universidade de origem e retribuir o investimento em seus estudos. Observaram que o tempo destinado à realização do estágio e à pesquisa foi pouco e sugeriram seu aumento. Sugeriram, ainda, maior comunicação entre as instituições ou, mesmo, a criação de uma rede a fim de viabilizar a realização de estágio em empresas e pesquisas aplicadas, bem como que haja um processo de acompanhamento e avaliação para os bolsistas de graduação sanduíche do programa Ciência sem Fronteiras.

TABELA 11 - Avaliação pelos egressos do desempenho geral da CAPES de bolsas concedidas para graduação sanduíche no período de 2011 - 2012 com atividades em 2012 - 2013

\begin{tabular}{cc}
\hline Avaliação & Percentual \\
\hline Ótimo & $20 \%$ \\
Bom & $52 \%$ \\
Regular & $22 \%$ \\
Fraco & $6 \%$ \\
Péssimo & $0 \%$ \\
\hline Total & $100 \%$ \\
\hline
\end{tabular}

Fonte: SisRel/CAPES/CGMR - Ano 2015

$\mathrm{Na}$ análise dos fatores que motivaram os bolsistas a participarem do estudo no exterior, como demonstra a Tabela 12 , nota-se que $24 \%$ motivaram-se para investir na futura carreira profissional, 14\% para conhecer outra cultura e melhor qualidade de ensino, 13\% para morar no exterior e 1\% para praticar um idioma estrangeiro. Nas respostas abertas, distinguem-se: "[...] O programa apresenta uma possibilidade ímpar na vida acadêmica do estudante. Não deve ser tratada como uma simples oportunidade de estudar em um país diferente, mas sim uma porta para um futuro que deve ser brilhante"; "[...] O estudante que for para o exterior deve estar focado em aprimorar suas habilidades acadêmicas e pessoais, visando ser um profissional com uma formação qualificada e diferenciada"; "[...] É uma oportunidade singular de crescer não apenas tecnicamente, mas, também, pessoalmente. Conhecer outras culturas e pessoas de outros países é uma maneira única de abrir a mente para o mundo e aprender a respeitar as diferenças culturais. Além disso, aproveitem também para desenvolver a língua do seu país de destino, isso vai ajudar muito na sua carreira profissional"; "[...] diria que o programa vai contribuir para a sua formação como cidadão brasileiro, e quando você retornar ao Brasil, terá 
mais vontade de modificar o nosso país e até mesmo melhorar o que já temos de bom, para que ele possa ser finalmente o país do futuro, com saúde, educação, transporte e segurança pública de qualidade, para que os brasileiros que não tiveram a mesma oportunidade de buscar um aperfeiçoamento no exterior, que possam fazer isso aqui mesmo".

TABELA 12 - Fatores que mais motivaram alunos à participação do estudo no exterior no período de 2011 - 2012 com atividades em 2012 2013

\begin{tabular}{cc}
\hline Avaliação & Percentual \\
\hline Aumentar a independência e autoconfiança & $9 \%$ \\
Conhecer outra cultura & $14 \%$ \\
Estabelecer uma rede de relacionamentos acadêmicos & $6 \%$ \\
Investir na futura carreira profissional & $24 \%$ \\
Melhor qualidade do ensino & $14 \%$ \\
Morar no exterior & $13 \%$ \\
Praticar um idioma estrangeiro & $1 \%$ \\
Outro(s) & $8 \%$ \\
\hline Avaliação & $\mathbf{1 0 0} \%$ \\
\hline
\end{tabular}

Fonte: SisRel/CAPES/CGMR - Ano 2015

Com referência à aferição dos bolsistas após o retorno dos estudos no exterior, mostrada na Tabela 13, observa-se que 19\% apreciaram o investimento na futura carreira profissional, $17 \%$ conhecer nova cultura e praticar um idioma estrangeiro, 14\% aumentar a independência e autoconfiança, 12\% morar no estrangeiro, $10 \%$ estabelecer uma rede de relacionamentos acadêmicos e melhor qualidade de ensino. É interessante ressaltar que, comparada à Tabela 12, nota-se que houve um equilíbrio na distribuição dos fatores, além de uma sensível diferença na avaliação anterior aos estudos no exterior. No fator praticar idioma estrangeiro, houve um acréscimo de 1\% para 17\%; estabelecer uma rede de relacionamentos acadêmicos aumentou de $6 \%$ para $10 \%$, enquanto que melhor qualidade decaiu de $14 \%$ para $10 \%$.

Pode-se observar que os bolsistas que participaram dessa consulta consideram que, realmente, o programa Ciência sem Fronteiras pode, de fato, contribuir para a melhoria da qualidade do ensino superior no Brasil, bem como para o desenvolvimento tecnológico e econômico do País. E alguns observaram o fato de haver muitos estudantes de outros países nas universidades em que estão alocados e refletiram que esse é o caminho encontrado para a difusão tecnológica nos países em desenvolvimento, ou seja, o contato de seus estudantes com a tecnologia presente em outras instituições de ensino e pesquisa e nas empresas. De fato, o programa Ciência sem Fronteiras objetiva colocar o Brasil dentro de um parâmetro internacionalmente estabelecido de Ciência, Tecnologia \& Inovação e concorda com a ideia de se focar na inovação e no fortalecimento da indústria para a geração de crescimento econômico e desenvolvimento social. A criação de uma cultura da inovação no país, incentivando a participação cada vez maior de estudantes, pesquisadores e empresários brasileiros na C,T\&I, se faz necessária para o sucesso do programa. 
TABELA 13 - Aspectos que o aluno mais apreciou após o período no período de 2011 - 2012 com atividades em 2012 - 2013

\begin{tabular}{cc}
\hline Avaliação & Percentual \\
\hline Aumentar a independência e autoconfiança & $14 \%$ \\
Conhecer outra cultura & $17 \%$ \\
Estabelecer uma rede de relacionamentos acadêmicos & $10 \%$ \\
Investir na futura carreira profissional & $19 \%$ \\
Melhor qualidade do ensino & $10 \%$ \\
Morar no exterior & $12 \%$ \\
Praticar um idioma estrangeiro & $17 \%$ \\
Outro(s) & $1 \%$ \\
\hline Avaliação & $\mathbf{1 0 0} \%$ \\
\hline
\end{tabular}

Fonte: SisRel/CAPES/CGMR - Ano 2015

Mediu-se o aproveitamento de créditos das disciplinas cursadas no exterior através das respostas extraídas dos relatórios de avaliações de aproveitamento de crédito ${ }^{9}$. Salienta-se, que os relatórios não são documentos para prestação de contas. São questionários exploratórios, compostos de questões abertas e fechadas, que visam avaliar as disciplinas cursadas no exterior. Dos 269 bolsistas investigados, 109 bolsistas não responderam os questionários.

Conforme Tabela 14 sobre 0 aproveitamento das disciplinas ${ }^{10}$ (BRASIL, 1979), observa-se que, dos respondentes, $29 \%$ das disciplinas foram aproveitadas, $19,33 \%$ foram aproveitadas parcialmente, $11,15 \%$ não foram aproveitadas e $40,52 \%$ não responderam ao questionário. Dentro das respostas abertas, destaca-se: "[...] É importante que o estudante saiba, antes de ir à universidade no exterior, quais serão as disciplinas e o curso que ele irá prestar [...]. Preparar o estudante é importante para que o mesmo agregue com suas qualidades e experiências, na faculdade de destino, os conhecimentos adquiridos durante a graduação no Brasil".

$\mathrm{Na}$ análise, dessa avaliação, consta que boa parte dos respondentes conseguiu convalidar as disciplinas cursadas no exterior, ou seja, dos 160 respondentes, 78 aproveitaram as disciplinas em sua IES de origem. Todavia, notase, que outra parte significante de bolsistas, ou seja, 52 bolsistas validaram parcialmente e 30 não conseguiram aproveitar as disciplinas cursadas no exterior. $O$ aproveitamento parcial e o não aproveitamento tem ocasionado atraso na conclusão dos estudos no Brasil, pois os egressos da graduação no exterior tiveram que cursar outras disciplinas para concluir seu curso, uma vez que aquelas cursadas não foram aproveitadas ou foram aproveitadas parcialmente nas universidades brasileiras.

\footnotetext{
9 Art. 47, § 2º, Lei de Diretrizes e Base (LDB) ํo 9.349, de 20/12/1996. Disponível em: $<$ https://www.planalto.gov.br/ccivil_03/Leis/L9394.htm> $<$ http://portal.mec.gov.br/index.php?option=com_content\&view=article\&id=12797\&ltemid=866>. Acesso em: 05.05.2015

${ }_{10}$ Resolução CFE o 5/79. Diário Oficial, Brasília, 17/07/1979. Seção I, pt. 1, p. 10.069. DOCUMENTA, Brasília (224):462, jul. 1979. Estabelece normas sobre aproveitamento de estudos. Disponível em: <http://portal.mec.gov.br/cne/arquivos/pdf/rcfe05_79.pdf>. Acesso em: 05.05.2015. 
TABELA 14 - Aproveitamento de disciplinas cursadas no exterior no período de 2011 - 2012 com atividades em 2012 - 2013

\begin{tabular}{ccc}
\hline Disciplinas & Bolsista & Percentual \\
\hline Aproveitadas & 78 & $29 \%$ \\
Parcialmente & 52 & $19,33 \%$ \\
Não aproveitadas & 30 & $11,15 \%$ \\
Não responderam & 109 & $40,52 \%$ \\
\hline Total Geral & $\mathbf{2 6 9}$ & $\mathbf{1 0 0}$
\end{tabular}

Fonte: SisRel/CAPES/CGMR - Ano 2015

Sobre a forma de aproveitamento das disciplinas que foram aproveitadas ou aproveitadas parcialmente, nota-se, conforme Tabela 15, que $23,05 \%$ foram aproveitadas como crédito obrigatório, $14,87 \%$ como créditos complementares, $10,41 \%$ como crédito optativo/módulo livre, $11,15 \%$ não foram aproveitadas e $40,52 \%$ não responderam ao questionário.

TABELA 15 - Forma de Aproveitamento de disciplinas cursadas no exterior no período de 2011 - 2012 com atividades em 2012 - 2013

\begin{tabular}{ccc}
\hline Disciplinas & Bolsista & Percentual \\
\hline Aproveitada como crédito obrigatório $^{11}$ & 62 & 23,05 \\
Aproveitada como créditos & & \\
complementares/optativos $^{12}$ & 40 & 14,87 \\
Aproveitada como crédito módulo livre $^{13}$ & 28 & 10,41 \\
Não aproveitada & 30 & 11,15 \\
Não responderam & 109 & 40,52 \\
\hline Total Geral & $\mathbf{2 6 9}$ & $\mathbf{1 0 0}$ \\
\hline
\end{tabular}

Fonte: SisRel/CAPES/CGMR - Ano 2015

Com referência aos motivos do não aproveitamento ou aproveitamento parcial das disciplinas cursadas no exterior, mostra-se, conforme Tabela 16, que 11,15\% não foram aproveitadas por serem disciplinas com formato/conteúdo distinto e, igualmente, $11,15 \%$ por não fazerem parte da grade curricular, e 8,18\% por serem já cursadas na IES brasileira. Os motivos do não reconhecimento dos créditos é um aspecto que demonstrou problema no momento de convalidação.

\footnotetext{
${ }^{11}$ As disciplinas obrigatórias são aquelas em que o estudante deverá ser matriculado e aprovado, ou ter obtido aproveitamento de estudos, para fins de integralização curricular do curso (GUIA DO CALOURO, 2015).

${ }^{12}$ As disciplinas optativas são aquelas integrantes do currículo do curso cujos créditos, em caso de aprovação, são considerados para fins de integralização curricular. O aluno pode escolher, da lista de disciplinas optativas do seu curso, aquelas ofertadas pelo próprio departamento ou ofertadas por outros departamentos (GUIA DO CALOURO, 2015).

${ }^{13}$ As disciplinas de módulo livre de um curso são todas as disciplinas de graduação que não são de abrangência restrita e que não constem no currículo do curso. Os créditos a integralizar em módulo livre são referentes às disciplinas ou atividades que não estão na lista de disciplinas obrigatórias nem de optativas do seu curso, porém estão previstas e são oferecidas. As disciplinas cursadas em módulo livre podem somar ao total de créditos exigidos para o curso, desde que estejam no limite máximo permitido pelo respectivo currículo (GUIA DO CALOURO, 2015).
} 
TABELA 16 - Motivos do não aproveitamento ou aproveitamento parcial das disciplinas cursadas no exterior no período de 2012 - 2013

\begin{tabular}{ccc}
\hline Disciplinas & Bolsista & Percentual \\
\hline Disciplinas com formato/conteúdo distinto $^{14}$ & 30 & 11,15 \\
Disciplinas já cursadas na IES brasileira & 22 & 8,18 \\
Disciplinas que não fazem parte da grade curricular brasileira & 30 & 11,15 \\
Aproveitadas & 78 & 29,00 \\
Não responderam & 109 & 40,52 \\
\hline Total Geral & $\mathbf{2 6 9}$ & $\mathbf{1 0 0}$
\end{tabular}

Fonte: SisRel/CAPES/CGMR - Ano 2015

As avaliações parecem indicar que é necessário buscar um consenso entre as IES brasileiras que participam do programa Ciência sem Fronteiras, tanto no aproveitamento do estágio quanto no aproveitamento dos estudos. Não parece adequado que as disciplinas ou estágios realizados no exterior não venham a contar na grade curricular dos ex-bolsistas de graduação. O Decreto № 7.642/2011 dispõe que cabe à instituição de origem do bolsista realizar o reconhecimento de créditos ou das atividades de treinamento no exterior, de acordo com o plano previsto. Portanto, para o sucesso das ações governamentais de internacionalização da educação brasileira, é mister a otimização dessas questões. A questão que se coloca, portanto, é: Qual seria a real finalidade de enviar o aluno para estudar fora do país se, em seu retorno, ele não aproveitasse quase nada desse estudo para completar sua grade curricular? É importante, para a continuidade do programa, que os estudantes tenham a confiança de que as instituições que fazem parte do programa garantam a decisão de revalidação automática das disciplinas cursadas no exterior. Dessa forma, obteremos um melhor desempenho político e institucional, ajustando a comunicação entre as instituições de ensino e as respectivas agências fomentadoras do programa.

No levantamento dos Currículos Lattes dos ex-bolsistas, aferiu-se a formação do bolsista após os estudos no exterior e em que medida os egressos seguiram a carreira acadêmica no país. Verificou-se que, conforme Tabela 17, 29,74\% dos bolsistas se graduaram, $1,49 \%$ se especializaram, $5,58 \%$ ingressaram no mestrado em IES brasileira, 5 bolsistas ingressaram no mestrado em IES estrangeira com bolsa/CAPES e 1 bolsista cursa doutorado com bolsa/CAPES. Pode-se observar que, somadas as formações dos bolsistas de graduação, especialização, mestrados e doutorado, atinge-se um total de 105 bolsistas concluíram suas graduações e 164 bolsistas estão com o curso em andamento.

TABELA 17 - Formação do bolsista de graduação sanduíche após os estudos no exterior no período de 2011 - 2012 com atividades em 2012 - 2013

\begin{tabular}{ccc}
\hline Graduação & Bolsistas & Percentual \\
\hline Em andamento & 164 & 60,97 \\
Graduação & 80 & 29,74 \\
Especialização & 4 & 1,49 \\
Mestrado/IES Brasileira & 15 & 5,58 \\
Mestrado/IES Estrangeira (CAPES) & 5 & 1,86 \\
Doutorado (CAPES) & 1 & 0,37 \\
\hline Total & $\mathbf{2 6 9}$ & $\mathbf{1 0 0}$ \\
\hline
\end{tabular}

Fonte: Plataforma Lattes CNPq. Acesso em março/2015 (Disponível em: http://lattes.cnpq.br/)

${ }^{14}$ Programa Ciência sem Fronteiras - Orientações - IFSP: Disponível em: http://www.ifsp.edu.br/index.php/arquivos/category/89-reitoria.html?download=10904\%3Amanualciencia-sem-fronteiras. Acesso em 05.05.2015. 
$\mathrm{Na}$ sequência do levantamento dos Currículos Lattes, analisaram-se as demandas profissionais dos respectivos bolsistas. Observou-se que (Tabela 18), $8,18 \%$ dos bolsistas obtiveram vínculo empregatício em empresa privada como celetistas, $3,35 \%$ em empresa pública, $1,86 \%$ em empresa privada como proprietários, $1,86 \%$, ou seja, 5 bolsistas na indústria, $26,39 \%$ estão como estagiários, $21,93 \%$ continuam como bolsistas/IES e $27,14 \%$ estão sem informação sobre seus vínculos.

Embora o estudo tenha apontado uma considerável conclusão do curso e um possível ingresso à carreira acadêmica, demonstraram-se pontos críticos e reflexivos das avaliações dos alunos e, com isso, espera-se não só realizar mais pesquisas medindo o crescimento econômico na inclusão dos ex-bolsistas de graduação no mercado brasileiro, como também avaliar até que ponto a internacionalização de seus estudos interferiu na escolha de continuidade de atividades acadêmicas e inserção na comunidade científica.

TABELA 18 - Inserção profissional de 269 bolsistas egressos do exterior no período de estudos 2012- 2013

\begin{tabular}{ccc}
\hline Vínculo Empregatício & Bolsista & Percentual \\
\hline Estágio & 71 & 26,39 \\
Bolsista/IES & 59 & 21,93 \\
Empresa Privada/CLT & 22 & 8,18 \\
Bolsista/CAPES & 14 & 5,20 \\
Empresa Pública/CLT & 9 & 3,35 \\
Empresa Privada/Proprietário & 5 & 1,86 \\
Indústria/CLT & 5 & 1,86 \\
Bolsista/CNPq & 5 & 1,86 \\
Empresa Pública/Servidor & 3 & 1,12 \\
Empresa Estrangeira/CLT & 2 & 0,74 \\
IES/CLT & 1 & 0,37 \\
*Sem informação & 73 & 27,14 \\
\hline Total & $\mathbf{2 6 9}$ & $\mathbf{1 0 0}$
\end{tabular}

Fonte: Plataforma Lattes CNPq. Acesso em março/2015 (Disponível em: http://lattes.cnpq.br/)

\section{CONCLUSÕES}

O estudo investigativo, realizado por meio deste trabalho, permitiu a verificação de importantes efeitos no desenvolvimento e comportamento dos alunos/bolsistas egressos da graduação sanduíche do programa Ciência sem Fronteiras. A investigação facilitou avaliar a trajetória e os resultados alcançados desses egressos e os motivos que os levaram a buscar a internacionalização de seus estudos. Após o término da pesquisa, foi possível determinar aspectos que se destacam como mais importantes sobre o tema, podendo considerar que os objetivos deste estudo foram alcançados, pois foi possível avaliar em que medida os egressos pretendem seguir a carreira acadêmica para mestrado e doutorado e têm atendidas as demandas profissionais do Brasil. 


\section{REFERÊNCIAS}

BRASIL. Decreto no 7.642, de 13 de dezembro de 2011. Institui o Programa Ciência sem Fronteiras. Disponível em: http://www.planalto.gov.br/ccivil_03/_Ato20112014/2011/Decreto/D7642.htm. Acesso em: 6 maio 2015.

BRASIL. Constituição (1988). Constituição da República Federativa do Brasil. Organização de Alexandre de Moraes. 16. ed. São Paulo: Atlas, 2000.

BRASIL. Lei de Diretrizes e Bases da Educação: Lei o 9.394/96, de 24 de dezembro de 1996. Estabelece as diretrizes e bases da educação nacional. Brasília, 1998.

BRASIL. Resolução CFE no 5, de 11 de julho de 1979. Estabelece normas sobre aproveitamento de estudos. Diário Oficial, Brasília, 17/07/1979. Seção I, pt. 1, p. 10.069. DOCUMENTA, Brasília (224):462, jul. 1979. Disponível em: <http://portal.mec.gov.br/cne/arquivos/pdf/rcfe05_79.pdf>. Acesso em: 5 maio 2015.

BRASIL. Programa Ciência sem Fronteiras. Disponível em: http://www.cienciasemfronteiras.gov.br/web/csf . Acesso em: 6.8.2015.

BRASIL. Universidade de Brasília. A UnB que você vê. Guia do Calouro 10 2015/ [coordenação do] Decanato de Ensino de Graduação; Diretoria Técnica de Graduação. - Brasília - Editoria UNB, 2014.125 p.; 21 cm. ISBN 978-85-230-1334-9. Disponível em: http://www.unb.br/administracao/diretorias/dds/guia.php . Acesso em: 8 agosto 2015.

CANTO FILHO, A. B.; FERREIRA, L. F.; BERCHT, M.; TAROUCO, L. M. R.; TAROUCO, L. M. R.; LIMA, J. V. Objetos de Aprendizagem no Apoio à Aprendizagem de Engenharia: Explorando a Motivação Extrínseca. RENOTE. Revista Novas Tecnologias na Educação, v. 10, p. 1-10, 2012. Disponível em: http://seer.ufrgs.br/index.php/renote/article/view/36390/23499. Acesso em: 6 maio 2015.

CAPES. Coordenação de Aperfeiçoamento de Pessoal de Nível Superior Programa Ciểncia sem Fronteiras. Disponível em: http://www.cienciasemfronteiras.gov.br/web/csf/graduacao_result - Acesso em: 29 jun. 2015.

CNPq - Conselho Nacional de Desenvolvimento Científico e Tecnológico Plataforma Lattes - Disponível em: http://lattes.cnpq.br/ Acesso em: 25 mar. 2015.

FERNÁNDEZ, E. Estudo dos ex-bolsistas inadimplentes de doutorado pleno no exterior: Motivos e causas de insucessos - caso CAPES 2012. Dissertação (Mestrado em Educação em Ciências) - Universidade Federal de Santa Maria, Rio Grande do $2012 . \quad$ Sul. 2 isponível em: http://cascavel.cpd.ufsm.br/tede/tde_busca/arquivo.php?codArquivo=4651. Acesso em: 30 mar. 2015.

FERNÁNDEZ1', E. ; NETO, I. R. A Inadimplência dos ex-bolsistas de doutorado pleno no exterior: causas de insucesso. Enciclopédia Biosfera, Centro Científico 
Conhecer - Goiânia, v.8, N.14; p. - 2012. Disponível em: http://www.conhecer.org.br/enciclop/2012a/multi/a\%20inadimplencia.pdf - Acesso em: 6.8.2015.

IPEA. Instituto de Pesquisa Econômica Aplicada - TD 1983 - Uma Proposta de Sistematização do Debate sobre Falta de Engenheiros no Brasil - Texto para Discussão. Rio de Janeiro: IPEA, 2014. Disponível em: http://www.ipea.gov.br/portal/images/stories/PDFs/TDs/td_1983.pdf. Acesso em: 6 maio 2015.

GUIMARÃES, J. A. In: site da CAPES - Conferência de Internacionalização das Universidades Brasileiras, realizada em 28 de julho de 2014. Disponível em: http://www.capes.gov.br/sala-de-imprensa/noticias/7090-internacionalizacao-dasuniversidades-brasileiras-e-tema-de-conferencia-na-reuniao-anual-da-sbpc). Acesso em: 30 mar. 2015.

MONTEIRO, R.C.M. Inserção internacional da produção de docentes da pósgraduação: um estudo na economia, ciência da computação e educação. Tese (Doutorado em Educação) - Universidade de Brasília (UnB), 2012. Disponível em: http://repositorio.unb.br/bitstream/10482/11238/1/2012_RoseCleideMendesMonteiro. pdf. Acesso em: 25 mar. 2015.

MOROSINI, M.C. Internacionalização na produção de conhecimento em IES brasileiras: cooperação internacional tradicional e cooperação internacional horizontal. Educação em revista, v. 27, n. 1, p. 93-112, 2011.

PRIORI, A. Universidade Pública e Competente. Revista Espaço Acadêmico. ano II, n. 12. Maio de 2002 - ISSN 151.6186 - Disponível em: http://www.espacoacademico.com.br/012/12angelo.htm. Acesso em: 5 jun. 2015.

PROGRAMA CIÊNCIA SEM FRONTEIRAS. Orientações aos participantes. Disponível em: http://www.ifsp.edu.br/index.php/arquivos/category/89reitoria.html?download=10904\%3Amanual-ciencia-sem-fronteiras - Acesso em: 5 maio 2015.

QS - TopUniversities - Worldwide university rankings, guides \& events Disponível em - http://www.topuniversities.com/university-rankings/world-universityrankings $/ 2013 \#$ sorting $=$ rank + region $=+$ country $=+$ faculty $=+$ stars $=$ false + search $=$.

Acesso em: 25 mar. 2015.

ROSA, L.. Cooperação Acadêmica Internacional: um estudo da atuação da CAPES. Dissertação (Mestrado em Ciências Sociais) - Centro de Pós-Graduação e Pesquisa das Américas da Universidade de Brasília. 2008. Disponível em: http://repositorio.unb.br/bitstream/10482/6289/1/2009_LeonardoOsvaldoBarchiniRoc ha.pdf. Acesso em: 6 maio 2015.

ROUSSEF, D. Programa de rádio "Café com a Presidenta", com a Presidenta da República, Dilma Rousseff - Por Rose Mary Rosendo - publicado em 30/09/2013, 00h00. Portal do Planalto. Disponível em: http://www2.planalto.gov.br/acompanhe-o- 
planalto/cafe-com-a-presidenta/cafe-com-a-presidenta_cafe-com-a-presidenta-3009-2013. Acesso em: 25 mar. 2015.

THE - Times Higher Education (UK): World University Rankings 2014-2015 Disponível em: https://www.timeshighereducation.co.uk/world-university-rankings/ Acesso em: 25 mar. 2015.

WEBOMETRICS (Espanha): Ranking Web of Word Universities - Disponível em: http://www.webometrics.info/es - Acesso em: 25 mar. 2015. 